\title{
OS DESAFIOS PARA ALCANÇAR A SUSTENTABILIDADE DO ESTADO FISCAL EM PERÍODO DE CRISE ECONÔMICA
}

\section{THE CHALLENGES TO ACHIEVE THE SUSTENTABILITY OF THE FISCAL STATE IN PERIOD OF ECONOMIC CRISIS}

\section{LUCIANA GRASSANO DE GOUVÊA MÉLO}

Doutora em Direito pela UFPE, com estágio pós-doutoral na Universidade de Bolgna, na Itália (CAPES). É professora da graduação, mestrado e doutorado em Direito da UFPE, ex-diretora da Faculdade de Direito do Recife/UFPE e Procuradora do Estado de Pernambuco.

\section{PEDRO DIAS DE OLIVEIRA NETTO}

Mestre em Direito pela UFPE. Atualmente é doutorando em Direito pela UFPE. Advogado. Conciliador voluntário do Centro Judiciário de Solução de Conflitos e Cidadania da JFPE (CEJUSC).

\section{RESUMO}

O artigo tem como objetivo analisar as principais características do estado fiscal, abordando uma perspectiva histórica sobre as atribuições do estado e a importância de arrecadar impostos como mecanismo de custeio das despesas estatais; bem como as repercussões que as crises econômicas acarretam na sustentabilidade do estado fiscal de diferentes formas, principalmente, na redução da arrecadação de impostos e no impacto social. A realidade dos países tem demonstrado que manter $\mathrm{o}$ atual modelo de estado fiscal, em um contexto econômico instável, exige grandes desafios diante das responsabilidades assumidas pelo setor público.

PALAVRAS-CHAVES: Estado fiscal; Sustentabilidade; Crise econômica; Impacto social. 


\section{ABSTRACT}

This paper has the aim of analyzing the main characteristics of fiscal state, approaching a historical perspective about the attributions of the state and the importance of collecting taxes as a mechanism to financing state expenditures; as well as the repercussions that economic crises cause into the fiscal state sustainability in different ways, mainly in the reduction of tax collection and social impact. The reality of the countries has shown that maintaining the current fiscal state model, in unstable economic scenario, demands considerable challenges in front of the responsibilities taken by the public sector.

KEYWORDS: Fiscal state; Sustainability; Economic crisis; Social impact.

\section{INTRODUÇÃO}

Embora sejam amplos e diversificados os debates sobre o Estado fiscal entre os doutrinadores pátrios e estrangeiros, o presente estudo limitar-se-á à análise de algumas características específicas do tema em cotejo.

Inicialmente, abordaremos uma perspectiva histórica da evolução das atribuições do Estado entre os séculos XVIII e XXI, em momento posterior ao período da Revolução Francesa até os dias atuais. Tal contexto permitirá uma compreensão conglobante das fases em que os Estados encontravam-se numa posição menos intervencionista até a transição para o período de maior intervenção econômica, na ampliação dos direitos fundamentais e fornecimento de maior número de serviços públicos.

Em sequência, serão estudados os elementos gerais que constituem a figura do Estado fiscal e sua distinção diante do Estado empresarial; a influência da teoria do contrato social, ressaltando a importância da organização em sociedade; bem como, o caráter solidário que envolve a figura dos impostos ${ }^{1}$ pagos coletivamente para a manutenção do Estado.

\footnotetext{
${ }^{1}$ Ao longo do texto serão feitas referências ao Estado fiscal como aquele que obtém as receitas através da arrecadação de impostos. No entanto, ressalvamos a existência de posicionamento divergente, cuja
} 
Por fim, o Estado fiscal será analisado sob o contexto da crise econômica e quais seriam as dificuldades encontradas pelos países em decorrência das responsabilidades assumidas em um cenário cada vez mais globalizado e de crescentes demandas advindas da sociedade.

Os desafios para o setor público e setor privado, bem como para os contribuintes individuais, também serão objetos de comparação para demonstrar os reflexos que as conjunturas, econômico-financeira e social, podem acarretar em diferentes perspectivas que repercutem na sustentabilidade do Estado fiscal contemporâneo.

Para tanto, imprescindível tornou-se uma revisão doutrinária, em especial, de autores de Portugal e do Brasil, abarcando uma visão histórica e atual para compreender as características do Estado fiscal ao longo das modificações sociais e econômicas.

\section{TRANSFORMAÇÕES DO PAPEL DO ESTADO (SÉCS. XVIII-XXI)}

O funcionamento do Estado e a forma pela qual são arrecadados recursos para a subsistência das suas atividades essenciais, ao longo do tempo, passaram por diversas transformações. As tendências econômicas adotadas pelos países desenvolvidos influenciaram, direta ou indiretamente, as formas de atuação dos Estados no cenário social e econômico.

Desse modo, é importante, ainda que de modo conciso e para melhor contextualização do tema em debate, mencionar a conjuntura em que as nações encontravam-se a partir do século XVIII até os tempos atuais.

Em primeiro momento, no período posterior à Revolução Francesa (17891799), o Estado Liberal arrimou-se como uma referência a ser seguida, sendo marcado pela forte abstenção do Poder Público. O Estado somente deveria atuar nas

figura do Estado fiscal não se cinge em torno apenas dos impostos, mas também na arrecadação de outras espécies de tributos, tais como taxas e contribuições. Reconhecemos que a arrecadação dos Estados recebe uma parcela das suas receitas de outros tributos, mas, em virtude da sua natureza unilateral, os impostos não conferem a quem paga o direito a uma contraprestação específica do Estado e, portanto, representam uma natureza solidária que é essencial à ideia de Estado fiscal. 
hipóteses em que sua presença fosse indispensável para garantir os direitos previstos na Declaração dos Direitos do Homem e do Cidadão que, em síntese, são os direitos à propriedade privada, liberdade, igualdade e fraternidade.

No contexto do liberalismo, a relação da tributação com a liberdade tem a característica de que o tributo era o preço a ser pago para que o cidadão ficasse livre das amarras do Estado. Se o Estado dá ao setor privado os fatores de produção, capital e trabalho, por meio da garantia de liberdade de exercício de profissão e da propriedade, há uma renúncia estatal no que tange ao seu interesse de atuar empresarialmente. Portanto, o Estado precisaria financiar-se através da cobrança de impostos, isto é, por uma participação nos lucros da economia privada (SCHOUERI, 2016, p. 35).

O Estado liberal, ou mínimo, caracteriza-se por arrecadar impostos apenas para financiar as despesas de serviços tipicamente públicos, tais como: a defesa nacional, a justiça e a administração. Desse modo, não há pretensão estatal em redistribuir rendimentos por meio da tributação, pois a redistribuição de riqueza seria uma consequência da atuação do livre mercado sem que o Estado interferisse nessa relação.

Importante trazermos à baila as lições de Saldanha Sanches (2010, p. 13) sobre a noção de justiça fiscal durante o período do Estado liberal. Nesta época, a ideia de justiça fiscal é estritamente próxima ao sentido de justiça tributária. Ou seja, esta corresponde apenas a uma avaliação quantitativa do modo como são partilhados os encargos entre os contribuintes, verificando a sua incidência entre aqueles com maiores ou menores rendimentos.

Não obstante, a participação mínima do Estado não foi suficiente para reduzir as desigualdades sociais e econômicas que se instalavam em grandes proporções, como consequência do liberalismo. As questões atinentes aos serviços de interesse social eram, por muitas vezes, repassadas ao setor privado sem qualquer forma de regulação ou fiscalização da atividade. Desse modo, o custo para a manutenção e funcionamento da máquina estatal era bastante reduzido e não dependia da arrecadação de elevada carga de impostos dos cidadãos.

As crises econômicas das primeiras décadas do século XX, principalmente, a crise decorrente da quebra da bolsa de valores de Nova lorque (1929), tornou-se um 
marco histórico pela consequência do impacto econômico negativo e substancial em diversos países.

Diante deste cenário de crescente preocupação e dos conflitos sociais que começavam a despontar, ocorreu o estopim para a realização de mudanças de paradigmas nos setores político e econômico, cujo principal aspecto cingia-se na presença de um Estado mais intervencionista.

Importante mencionar neste momento que, em 1936, foi publicado o livro "Teoria geral do emprego, do juro e da moeda", por John Maynard Keynes, cujas principais teorias foram utilizadas após a crise de 1929 como base para as medidas de recuperação econômica dos EUA, adotadas pelo presidente norte-americano Roosevelt no programa governamental do New Deal, oferecendo um claro argumento para a intervenção estatal na economia, principalmente pela utilização da política fiscal (BLANCHARD, 2004, p. 576).

Sem olvidar, ainda, o período conturbado vivenciado nesta época em decorrência dos conflitos bélicos em diversas partes do mundo onde, somado com os outros fatores, necessitava de mudanças na concepção e atuação do Estado para assegurar amplos direitos sociais e reduzir as desigualdades econômicas.

Em substituição ao modelo pretérito, ganha força entre os países o modelo do Estado do Bem-Estar Social (Welfare State) com grandes referências à Constituição Mexicana de 1917 e à Carta Alemã de Weimar. Este modelo de Estado defendia a atuação ativa do Estado na busca da justiça social e, para tanto, centralizava e ampliava a realização de serviços públicos.

Para atingir as metas de intervenção do Poder Público e garantir o bem-estar social, fez-se necessário ampliar a estrutura administrativa e as atribuições do Estado. Destarte, este modelo estabeleceu monopólios estatais na economia, aumentou a burocracia estatal, e, diante das novas atribuições, elevaram-se bastante as despesas públicas. Por conseguinte, houve a necessidade de um aumento na arrecadação de impostos para suprir as novas demandas.

Conforme bem esclarece Luís S. Cabral de Moncada (2007, p. 32), o Estado do Bem-Estar Social ampliou sua esfera de atuação passando a abranger setores econômicos em que até então não havia a participação pública. A intervenção do Estado, portanto, não se restringiu apenas em fornecer serviços públicos tradicionais. 
Foi além. Alcançou setores não apenas sociais, mas também aqueles setores cuja participação privada detinha a atuação isolada.

No Estado social o papel da tributação também foi ampliado, não se limitando apenas na preocupação em arrecadar conforme a capacidade contributiva dos indivíduos. Busca-se, também, realizar a redistribuição da riqueza para reduzir as desigualdades sociais.

Por oportuno, mencionamos interessante remate lançado por Saldanha Sanches (2010, p. 14-15), ao abordar o processo social de redistribuição de riqueza, o autor aduz que a justiça na tributação e a justiça na distribuição adquirem o mesmo grau de importância, pois quando uma pessoa utiliza gratuitamente um serviço público, o Estado está concedendo um rendimento em espécie que foi redistribuído da esfera patrimonial dos contribuintes de maior capacidade econômica, na situação do sistema tributário garantir uma tributação isonômica.

Destarte, a justiça fiscal, no contexto do Estado social, também considera aspectos relativos à despesa pública, pois o modo como o Estado irá gastar os impostos arrecadados se reflete em maior ou menor provimento dos direitos sociais aos cidadãos.

Em meados da década de 1980, contudo, diferentes fatores contribuíram de modo gradual e com aspectos distintos para o abrandamento do Welfare State. Nos países industrializados, a crise fiscal, provocada pelos elevados gastos públicos, agravou as divergências entre o Poder Público, empresários e trabalhadores, que almejavam assegurar os direitos conquistados.

A partir de então desenvolve-se a ideia da necessidade de descentralizar o Estado, reduzindo a estrutura administrativa para diminuir as despesas públicas. A descentralização governamental advém, em grande parte, do movimento estruturado no Reino Unido, denominado de New Public Management (NPM). Tal tendência visava modernizar a organização administrativa através da adaptação e transferência dos conhecimentos gerenciais desenvolvidos no setor privado para o público, objetivando a redução do tamanho da máquina administrativa para dar ênfase no aumento de sua eficiência (PECI; PIERANTI; RODRIGUES, 2008, p. 39-55).

Somada à reforma administrativa também ocorreu uma mudança de paradigma na participação ativa do Estado no setor econômico para um modelo de 
Estado Neoliberal, caracterizado, principalmente, pelos fenômenos da privatização e liberalização.

Não obstante a tendência da liberalização econômica existente neste período, o Poder Público adquire importantes instrumentos para a intervenção reguladora do mercado, através da criação de entes reguladores independentes, para combater a formação de monopólios e oligopólios, defendendo as regras da concorrência, bem como de mecanismos de intervenção para mitigar as falhas de mercado, tais como: as assimetrias de informações, externalidades negativas e os custos das transações. Também, estabelece-se atribuição ao Poder Público para supervisionar a qualidade das atividades econômicas desenvolvidas e a aplicação de sanção às infrações cometidas.

Ademais, é possível afirmarmos que a intervenção do Estado não é hoje tão reduzida em comparação com o que era antes da liberalização econômica: apenas, ela é exercida de forma diferente (OTERO, 2003, p. 302).

\section{O ESTADO FISCAL CONTEMPORÂNEO}

O primeiro elemento imprescindível é analisar em que consiste a figura do Estado fiscal. Diversos países apoiam-se na fiscalidade como forma majoritária de arrecadar recursos através dos impostos cobrados aos seus cidadãos.

Não obstante, há exceção ao Estado fiscal na hipótese em que o país configura-se como verdadeiro Estado proprietário, produtor ou empresarial. Estes Estados são considerados não fiscais, pois a sua base financeira consiste, em grande parte, nos rendimentos da atividade econômica monopolizada pelo Estado, e não em impostos pagos pelos contribuintes com base na sua capacidade econômica (NABAIS, 2015, p. 193).

Ainda, há Estados em que suas receitas são originárias da exploração de matérias-primas tais como o petróleo, gás natural, ouro, etc., e, portanto, podem reduzir, ou até mesmo dispensar, que seus cidadãos recolham impostos para custear as principais atividades estatais. Ressalvadas as exceções, é possível afirmarmos que, majoritariamente, os Estados contemporâneos são Estados fiscais. 
Para compreender o papel do Estado fiscal e a sua sustentabilidade através dos impostos cobrados aos cidadãos é preciso reconhecer que esta responsabilidade, a manutenção dos direitos e custeio de serviços básicos, ocorre desde as origens da noção de sociedade. Tal fato pode ser verificado, ainda que de modo incipiente, através das teorias contratualistas desenvolvidas por Thomas Hobbes, John Locke e Jean-Jacques Rousseau ao analisar o instituto do "contrato social", ainda que sob diferentes perspectivas teóricas.

O contrato social permitiu a união dos indivíduos para diminuir os custos econômicos necessários para a proteção individual dos seus direitos. Em compensação, todos deveriam contribuir para uma entidade central (o que mais tarde viria a se tornar o que hoje conhecemos por "Estado"), através de diversas formas de atividades, e que estas contribuições coletivas (pecuniárias e não-pecuniárias) pudessem custear a proteção e o fornecimento de serviços de modo mais eficiente.

Desse modo, a tributação há de ser encarada como um negócio celebrado entre o Estado e o indivíduo, necessitando do consentimento deste para que seja instituído determinado imposto. Se a cobrança fosse exigida de modo unilateral e não consensual pelo Estado, este estaria violando o direito fundamental de proteção à propriedade.

Não obstante, diante das novas concepções do papel do Estado, os impostos também devem possuir uma natureza solidária, superando a perspectiva individualista verificada na teoria do contrato social. O valor cobrado pelo imposto não poderia ser um valor muito elevado, devendo condizer com a capacidade contributiva de cada indivíduo. Tampouco, o valor poderia ser equivalente ao preço dos serviços públicos usufruídos por cada contribuinte, pois ficaria prejudicada a ideia de solidariedade que está na base de formação dos Estados fiscais contemporâneos (NABAIS, 2005, p. 2729).

Destarte, dando sequência ao estudo sobre as características do Estado fiscal, no que tange à passagem do Estado Liberal (menos intervencionista) para o Estado Social (com maior atuação estatal no fornecimento de serviços públicos e na economia), faz-se importante mencionar o posicionamento de José Casalta Nabais (2015, p. 194) que defende a compatibilidade do modelo de financiamento por meio de impostos para as duas formas de atuações estatais. 
Nesse contexto, o Estado fiscal compreende tanto o Estado liberal como o Estado social, pois a divergência cinge-se à pretensão de limitar, ou ampliar, a forma de atuação e dimensão estatal, não interferindo na questão sobre o meio pelo qual são obtidos os recursos públicos.

Mas não podemos olvidar que no Estado social, diante da miríade de atribuições e direitos sociais providos, subsiste maior necessidade em ampliar a arrecadação dos impostos. Em diversos países a manutenção dos direitos sociais e individuais é a base legitimadora do modelo estatal contemporâneo, pois, em decorrência dos seus aspectos coletivos e difusos, sem estes direitos os alicerces do próprio Estado seriam afetados diante das dificuldades daí advindas para a operacionalidade do princípio democrático (NABAIS; SILVA, 2011, p. 24).

\section{A SUSTENTABILIDADE DO ESTADO FISCAL EM PERÍODO DE CRISE ECONÔMICA}

A perspectiva da sustentabilidade do Estado fiscal tem uma concepção multifacetada. José Casalta Nabais (2015, p. 117) nos dá conta que a sustentabilidade, no seu quadro mais amplo, "reporta-se à ideia de homeostase como a capacidade biológica e institucional de promover o equilíbrio dinâmico que propicie o bem-estar sustentável num quadro de longevidade e qualidade subjetiva de vida".

Diante deste pluralismo metodológico que deve ser compreendido na análise do viés da sustentabilidade, para o objetivo a que se propõe o presente estudo, enfatizaremos duas perspectivas: primeira, sob o enfoque da sustentabilidade vista pela dimensão econômico-financeira, verificaremos as repercussões da crise econômica no contexto da relação entre Estado e mercado; em seguida, analisaremos a sustentabilidade sob a perspectiva social, principalmente, no combate às desigualdades sociais que tornam-se acentuadas em períodos de recessão econômica e políticas de austeridade.

A percepção da sustentabilidade econômico-financeira inicia-se, então, partindo da premissa de que tanto o Estado de atuação mais ampla quanto de 
intervenção diminuta, sempre dependem de recursos financeiros para custear suas despesas.

Conforme observa Marcelo Rodrigues Siqueira (2011, p. 130), a realidade dos países tem demonstrado que manter o atual modelo de Estado fiscal tem um custo elevado diante das inúmeras responsabilidades assumidas pelo ente público, tais como: educação, saúde, previdência e assistência social, cultura, serviços públicos e de infraestrutura, políticas públicas de redistribuição de renda, etc.

O Estado fiscal contemporâneo também presencia o estreitamento das suas bases tributárias causado pela intensificação de circulação de pessoas, produtos, serviços e capitais. Esses fatos podem ser, em grande parte, decorrentes da globalização e dos efeitos das inovações tecnológicas que diminuíram os custos dos transportes, das comunicações, e, inclusive, por consequência da redução das restrições das barreiras migratórias de diversos países.

Os cidadãos de determinados países preferem migrar para desenvolver suas atividades econômicas em outro Estado que esteja apto para atender aos anseios individuais e profissionais. Tal fato pode acarretar a redução da mão de obra jovem, e, desse modo, ocasionar um déficit nos custeios das despesas públicas, em especial, nos gastos com a previdência e a saúde.

Há de se reconhecer, no entanto, que este contexto globalizado também abrange aspectos importantes sobre o combate à fraude e à evasão fiscais, bem como, aos efeitos negativos da concorrência fiscal desleal entre os Estados, sendo essas atividades, em grande parte, responsáveis pela erosão da base tributável dos países, aumentando ainda mais o impacto nas despesas públicas.

Cada vez mais os Estados utilizam mecanismos de cooperação internacional para mitigar os prejuízos acarretados pela sonegação fiscal, evasão de divisas, lavagem de dinheiro, etc. Ao utilizar instrumentos eficientes, como, por exemplo, o intercâmbio internacional de informações fiscais, que permitam promover um nível elevado de transparência e sejam capazes de identificar o patrimônio, rendimentos e as atividades econômicas dos contribuintes, um grande passo é dado para alcançar a 
efetivação do princípio da isonomia material e da capacidade contributiva, bem como inibir a prática de atividades ilícitas².

Também, não podemos olvidar que o processo de integração dos mercados financeiros mundiais abrange não só a possibilidade do aumento dos lucros diante dos investimentos estrangeiros, e, consequentemente, da arrecadação de impostos, mas repercute na internacionalização dos riscos, fazendo com que eventuais prejuízos se alastrem mais rapidamente por todos os continentes, como ocorreu nas recentes crises financeiras (SIQUEIRA, 2011, p. 134-135).

A título de exemplo, podemos mencionar a crise econômica de 2008. A bolha imobiliária dos EUA, acarretada pela falta de regulação do mercado de hipotecas aliado às taxas de juros baixas do governo norte-americano, ocasionou prejuízos financeiros que repercutiram na economia mundial.

A crise econômica pode ocasionar algumas consequências para o Estado. Uma delas trata-se do aumento do déficit público em razão da diminuição geral da atividade econômica, seja por conta do fechamento de empresas ou através da redução do consumo, provocando uma baixa na arrecadação tributária e um incremento no gasto público com o aumento das prestações sociais (por exemplo, aumento nos casos de seguro-desemprego).

Analisando o atual cenário de crise fiscal e econômica do Brasil, de fato, há certa semelhança com as crises econômicas que ocorrem em outros países. A dificuldade em equilibrar o orçamento público é uma questão bastante complexa, pois, ao mesmo tempo em que o Estado precisa aumentar a arrecadação, seja através dos impostos ou outra espécie de tributo, para garantir a manutenção dos serviços públicos e o funcionamento das atividades administrativas, há um reflexo desta medida na

\footnotetext{
2 Para melhor compreensão da importância do papel referente ao intercâmbio de informações fiscais, remetemos o leitor ao artigo publicado por Luciana Grassano Melo (2017, p. 159-173): Intercâmbio de Informação contra a Fraude e Evasão Fiscal. No cenário nacional, é possível verificar que o Brasil já aderiu a diversos tratados internacionais em matéria de intercâmbio de informações fiscais entre mais de cem países signatários, por exemplo: a "Convenção Multilateral sobre Assistência Mútua Administrativa em Matéria Fiscal" e a "Convenção para Troca Automática de Informação Financeira em Matéria Tributária". Ainda, podemos mencionar a adesão do Brasil ao Programa BEPS, desenvolvido pela Organização para a Cooperação e Desenvolvimento Econômico (OCDE), que tem como propósito evitar os efeitos negativos da concorrência fiscal desleal entre Estados soberanos, especialmente no tocante aos paraísos fiscais.
} 
economia privada através da redução dos recursos disponíveis para investimentos privados e, por conseguinte, uma desaceleração do $\mathrm{PIB}^{3}$.

Diante de uma análise incipiente podemos constatar que o cenário de instabilidade política e a perda de liquidez das principais empresas da engenharia civil em decorrência das investigações criminais que recaíram sobre seus sócios, ocasionaram a estagnação das obras de infraestrutura e desempregos em massa no Brasil. Esse contexto contribuiu para que os investimentos fossem adiados ou transferidos para outros países que apresentem uma maior estabilidade.

Outro aspecto decorrente da atual crise fiscal vivenciada pelos Estados cingese na diversificação da despesa pública que pode ocorrer de modo direto ou indireto, por meio da concessão de benefícios fiscais. As despesas decorrentes de benefícios fiscais representam um pagamento passivo realizado pelo Poder Público em favor do setor privado mediante a redução dos impostos que deveriam ser arrecadados.

Ainda, em período recente, seja em âmbito federal ou estadual, foi adotada uma forte política de benefícios fiscais sem possuir um adequado estudo dos impactos destas medidas expansionistas. Foram concedidos incentivos fiscais ${ }^{4}$ e créditos para juros subsidiados sem que, de outro lado, houvesse uma preocupação com as renúncias dessas receitas e o aumento das despesas públicas ou, até mesmo, um controle eficiente dos resultados que estas medidas propiciaram à sociedade.

No que tange à relação entre Estado e mercado, há de se ressaltar que a crise econômico-financeira pode ter origem tanto do setor privado que, ao apresentar um baixo desempenho, necessita da ajuda do Estado, através da concessão de benefícios fiscais, para fomentar o crescimento da atividade produtiva; ou do setor público, diante

\footnotetext{
${ }^{3}$ Produto interno bruto (PIB) é o valor de mercado de todos os bens e serviços finais produzidos em um país, em um dado período. Nas ciências econômicas, os economistas estudam a composição do PIB de acordo com diversos tipos de gastos. Desse modo, o PIB é dividido em quatro componentes: consumo (despesas do setor privado); investimento (compras de bens de capital, estoques e estruturas); compras (gastos em bens e serviços) do governo; e as exportações líquidas. (MANKIW, 2014, p. 468-472).

4 Para melhor compreensão do campo de atuação financeira dos incentivos fiscais, utilizamos como referência as lições de Ricardo Lobo Torres (1995, 293-294), ao afirmar "que os incentivos que operam na vertente da receita estão em simetria e podem ser convertidos em privilégios financeiros, a gravar a despesa pública. A diferença entre eles é apenas jurídico-formal. A verdade é que a receita e a despesa são entes de relação, existindo cada qual em função do outro, donde resulta que tanto faz diminuir-se a receita pela isenção ou dedução, como aumentar-se a despesa, pela restituição ou subvenção, que a mesma consequência será obtida: o empobrecimento do ente público e o enriquecimento do contribuinte".
} 
do cenário de instabilidade no orçamento público, vez que as despesas superam as receitas, fazendo com que haja um impacto nos investimentos privados: seja pela cobrança de mais impostos (o que reduz a renda disponível no mercado para investir), ou através das restrições estabelecidas por órgãos internacionais, que dificultam a entrada de capital estrangeiro nos países de alto risco para investimentos.

De igual importância, a bem da verdade, a sustentabilidade do Estado fiscal também pode ser analisada sob a perspectiva da sociedade, especialmente, no combate às desigualdades sociais. Sabe-se que os efeitos decorrentes da crise econômica são fortes e acarretam um maior impacto na vida dos cidadãos, em grande parte, nos mais desprotegidos economicamente, que veem uma constante redução na prestação de serviços públicos. Desse modo, há uma ampliação do quadro de desigualdade social, vez que as camadas mais privilegiadas pouco sentem os efeitos da política de austeridade (REIS, 2014, p. 16).

Assim como vem acontecendo no Brasil e já aconteceu em diversos países europeus como, por exemplo, Portugal, em momentos de crise econômica os Estados voltam a atenção apenas para a despesa pública, através de cortes orçamentários em diversos setores, inclusive, naqueles setores que são essenciais para garantir a manutenção de direitos sociais, a saúde, educação e previdência, acentuando uma distribuição dos efeitos da crise numa perspectiva regressiva.

De extrema importância a observação de Pedro Hespanha, Sílvia Ferreira e Vanda Pacheco (2014, p. 243), quando destacam que a distribuição de riqueza por meio do fornecimento de serviços públicos não aumenta o rendimento financeiro disponível das famílias, mas são indispensáveis na promoção da garantia dos direitos sociais e na luta contra a pobreza. Por consequência, quanto maiores forem as desigualdades econômicas de partida, frisa-se a situação em que o Brasil se insere, maior será o efeito equalizador proporcionado pelos serviços públicos existentes.

Em um cenário de políticas de austeridade baseada em contenção pela despesa pública e a consequente retração nas transferências sociais, não só há um retrocesso no combate à pobreza, como também serão acentuadas as desigualdades econômicas e sociais já existentes, pois aqueles que conseguiram uma melhor qualidade de vida terão os seus direitos e rendimentos tolhidos diante de uma redução dos serviços públicos e das modificações legislativas que importem em supressão de 
benefícios sociais, como, por exemplo, as que ocorrem na legislação previdenciária e trabalhista.

Faz-se imprescindível refletir e debater seriamente sobre qual política econômica deve ser adotada em momentos de crise. Pois se quisermos contribuir para um verdadeiro modelo de desenvolvimento sustentável, seja sob uma perspectiva econômica ou social, será preciso criar oportunidades para todos por meio de um modelo de funcionamento da economia socialmente mais justo, repartindo os ônus da crise de forma a contemplar, conforme já mencionado, a isonomia material e a capacidade contributiva (HESPANHA; FERREIRA; PACHECO, 2014, p. 245).

Não se deve olvidar que a sustentabilidade social tem por base a ideia de que, em períodos de crise econômica, é preciso evitar que seja adotada uma política de austeridade de natureza excludente, protegendo apenas as camadas sociais mais favorecidas. Deve-se permitir uma maior isonomia do sacrifício a ser suportado pelos diversos setores da sociedade por meio de uma tributação justa e progressiva (SANCHES, 2010, p. 32).

Mister que se faça, ainda que com brevidade, referência a outro ponto imprescindível ao tratar da sustentabilidade social, no que tange à distribuição dos encargos fiscais pelos diversos grupos de contribuintes. Destarte, é possível encontrar aquilo que José Casalta Nabais (2011, p. 36) chama de apartheid fiscal. Essa situação, segundo o autor, refere-se não apenas ao montante total dos impostos arrecadados, mas também aos deveres acessórios que os contribuintes têm de suportar.

Nesse contexto, podem ser encontrados dois grupos de contribuintes: primeiro, os trabalhadores dependentes que pagam os impostos instituídos com base na sua capacidade contributiva, bem como, os impostos indiretos de forma regressiva, sem qualquer benesse fiscal; segundo, as empresas que, em virtude dos benefícios fiscais já existentes que podem escolher, ou, por meio de influências políticas através de grupos de pressão, obter novos benefícios, acabam pagando menos impostos do que os demais contribuintes (NABAIS, 2011, p. 36).

Nos Estados fiscais contemporâneos apenas uma pequena parcela dos contribuintes tem condições de elaborar um planejamento fiscal eficiente. Aqueles que dispõem de uma boa assessoria jurídica e contábil conseguirão, licitamente, desonerarem-se dos complexos encargos fiscais. Sem olvidarmos, inclusive, práticas 
deletérias realizadas por grupos empresariais para influenciar na distribuição dos benefícios fiscais concedidos em proveito próprio através da captura econômica dos parlamentares. De outro lado, o Estado para manter a sua capacidade de arrecadação pode acabar por sobrecarregar os demais contribuintes.

Conforme bem observa Saldanha Sanches (2010, p. 43), as normas tributárias são compostas por um conjunto de exceções, de regimes especiais, de benefícios fiscais que não são de fácil conhecimento da grande maioria dos contribuintes. Desse modo, as assimetrias de informações da legislação tributária permitem que apenas um pequeno grupo tenha conhecimento técnico para participar e opinar na formação das leis, favorecendo que sejam concedidos benefícios fiscais a apenas um grupo restrito de contribuintes.

Há de se considerar que a concessão de um incentivo fiscal, sem que exista uma verdadeira justificativa em benefício à coletividade, transforma-se em um elevado custo para todos, vez que na medida em que desonera alguns contribuintes, acaba por aumentar os efeitos decorrentes da renúncia de receita aos demais para compensar o valor que foi deixado de arrecadar.

O que se constata, pois, é que tal fato não reflete uma verdadeira justiça fiscal. Os cidadãos com menores condições econômicas acabam pagando uma carga tributária maior ao comparar a proporção entre a renda e o patrimônio real e o imposto pago por aqueles que dispõem de maior capacidade contributiva, caracterizando, assim, um sistema tributário regressivo e injusto.

Deve-se, em verdade, principalmente em países como o Brasil, vez que há uma elevada desigualdade social, exercer uma tributação progressiva com base nos princípios da isonomia material e da capacidade contributiva, pois, desse modo, o custo da sustentabilidade do Estado fiscal é absorvido proporcionalmente sobre as camadas da sociedade: não sobrecarregando a base dos contribuintes, formada por aqueles de pouca capacidade contributiva, e arrecadando mais impostos do topo, haja vista os altos rendimentos que dispõem e o dever de solidariedade no que tange à redistribuição de riquezas. 


\section{CONCLUSÃO}

Destarte, a partir do exposto, é possível alçar algumas conclusões objetivas:

(1) O papel do Estado na vida social e econômica passou por diversas modificações ao longo do tempo. Seja sob uma roupagem de Estado liberal, Estado do bem-estar social, ou de Estado neoliberal, as receitas arrecadadas pelos impostos são essenciais para a sustentabilidade do Estado fiscal;

(2) O Estado fiscal tem como desígnio a arrecadação de receitas através dos impostos. Tais impostos representam o preço a ser pago seja para se alcançar uma sociedade justa e solidária, fornecer serviços públicos, custear as atividades administrativas;

(3) Hodiernamente muitos países experimentam uma modificação das suas bases tributárias em decorrência da intensificação de circulação de pessoas, produtos, serviços e capitais que foi proporcionada pela globalização;

(4) Ainda, o processo de integração dos mercados financeiros mundiais, sendo este um dos efeitos da globalização, abrange não só a possibilidade do aumento da arrecadação dos impostos, em decorrência dos novos investimentos estrangeiros, mas também repercute na internacionalização dos riscos, pois os prejuízos financeiros irão se alastrar com mais rapidez para outros países, afetando as contas públicas diante da consequente queda das atividades econômicas desenvolvidas no país;

(5) No que tange à relação entre Estado e mercado, a crise econômicofinanceira pode ter origem tanto do setor privado que, ao apresentar um baixo desempenho, necessita da ajuda do Estado, através da concessão de incentivos fiscais, para fomentar o crescimento da atividade produtiva; ou do setor público, diante do cenário de instabilidade no orçamento público, fazendo com que haja um impacto nos investimentos privados: seja pela cobrança de mais impostos, ou através das restrições estabelecidas por órgãos internacionais, que dificultam a entrada de capital estrangeiro nos países de alto risco para investimentos;

(6) A sustentabilidade do Estado fiscal também deve ser analisada sob a perspectiva da sociedade, especialmente, no combate às desigualdades sociais. Os efeitos decorrentes da crise econômica são fortes e acarretam um maior impacto na vida dos cidadãos, em grande parte, nos mais desprotegidos economicamente, que 
vêem uma constante redução na prestação de serviços públicos. Desse modo, há uma ampliação do quadro de desigualdade social, vez que as camadas mais privilegiadas pouco sentem os efeitos das políticas de austeridade;

(7) Faz-se imprescindível refletir e debater seriamente sobre qual política econômica deve ser adotada em momentos de crise. Pois se quisermos contribuir para um verdadeiro modelo de desenvolvimento sustentável, seja sob uma perspectiva econômica ou social, será preciso criar oportunidades para todos por meio de um modelo de funcionamento da economia socialmente mais justo, repartindo os ônus da crise de forma a contemplar a isonomia material e a capacidade contributiva;

(8) Em países com uma elevada desigualdade social como o Brasil, deve-se com mais razão ainda exercer uma tributação de base progressiva, pois, assim, o custo da sustentabilidade do Estado fiscal passa a ser absorvido isonomicamente sobre as variadas camadas da sociedade, o que requer também mais eficiência e controle dos benefícios fiscais concedidos e uma tributação indireta em patamares mais razoáveis do que os que o sistema tributário brasileiro atualmente apresenta.

\section{REFERÊNCIAS}

BLANCHARD, Olivier. Macroeconomia. São Paulo: Pearson Prentice Hall, 2004.

MANKIW, N. Gregory. Introdução à economia. São Paulo: Cengage Learning, 2014.

MELO, Luciana Grassano de Gouvêa. Intercâmbio de informação contra a fraude e evasão fiscais. Revista Jurídica - UNICURITIBA, vol. 2, n. 47, p. 159 a 173, 2017. Disponível em: $<$ http://revista.unicuritiba.edu.br/index.php/RevJur/article/view/2031/1310>. Acesso em: 30 de setembro de 2018.

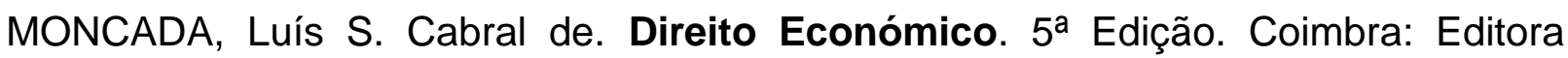
Coimbra, 2007.

NABAIS, José Casalta; SILVA, Suzana Tavares da. (coords.). Sustentabilidade fiscal em tempos de crise. Coimbra: Almedina, 2011.

NABAIS, José Casalta. Por um estado fiscal suportável: estudos de direito fiscal. Coimbra: Almedina, 2005.

O dever fundamental de pagar impostos. Coimbra: Almedina, 2015. 
Estudos de direito fiscal. Vol. IV. Coimbra: Almedina, 2015.

OTERO, Paulo. Legalidade e Administração Pública: o sentido da vinculação administrativa à juridicidade. Coimbra: Almedina, 2003.

PECI, Alketa; PIERANTI, Octavio Penna; RODRIGUES, Silvia. Governança e new public management: convergências e contradições no contexto brasileiro. Organizações \& Sociedade, Salvador, v. 15, n. 46, p. 39-55, Set. 2008.

REIS, José (Coord.). A economia política do retrocesso: crise, causas e objectivos. Coimbra: Almedina, 2014.

SANCHES, Saldanha. Justiça fiscal. Lisboa: FFMS, 2010.

SCHOUERI, Luís Eduardo. Direito tributário. 6ª Ed. São Paulo: Saraiva, 2016.

TORRES, Ricardo Lobo. Os direitos humanos e a tributação. Rio de Janeiro: Renovar, 1995. 